\title{
Implementasi dan Evaluasi Visualisasi Data Interaktif pada Publikasi Laporan Bulanan Data Sosial Ekonomi Indonesia
}

\author{
(Implementation and Evaluation of Interactive Data Visualization in the Publication of Indonesia's \\ Socio-Economic Data Monthly Report) \\ Hafidz Isa Nasruddin Lizana ${ }^{1}$, Farid Ridho ${ }^{2}$ \\ ${ }^{1,2}$ Politeknik Statistika STIS \\ Jalan Otto Iskandardinata No.64C, RW.4, Bidara Cina, Jatinegara, Kota Jakarta Timur, DKI Jakarta 13330 \\ E-mail: 221709724@stis.ac.id
}

\begin{abstract}
ABSTRAK
Setiap bulan Badan Pusat Statistik (BPS) mempublikasikan buku Laporan Bulanan Data Sosial Ekonomi (LBDSE) Indonesia, dimana di dalam publikasi tersebut berisi perkembangan dari 18 topik data beserta visualisasinya. Namun, visualisasi data pada publikasi LBDSE tidak lengkap dan hanya bersifat statis, sedangkan data yang ada memiliki dimensi/variabel yang cukup besar. Sehingga peneliti berfikir untuk mengimplementasikan visualisasi data interaktif publikasi LBDSE pada SIVIS LBDSE agar memudahkan dalam memahami data-data nya. Untuk menilai keberhasilan tujuan pengimplementasian tersebut, peneliti akan melakukan evaluasi terhadap visualisasi data pada SIVIS LBDSE berdasarkan penilaian pengguna menggunakan 8 indikator penilaian yang diadopsi dari penelitian terdahulu. Tujuan penelitian ini yaitu untuk mengimplementasikan visualisasi data interaktif pada data LBDSE, mengevaluasi visualisasi data pada SIVIS LBDSE, serta mengetahui visualisasi data terbaik terhadap data kategorik publikasi LBDSE. Dengan bantuan 50 responden, mereka menilai bahwa visualisasi data pada SIVIS LBDSE memiliki keunggulan dan kekurangannya masing-masing berdasarkan 8 indikator penilaian yang digunakan. Namun secara keseluruhan responden mengurutkan visualisasi data terbaik untuk data kategorik secara berturut-turut yaitu, Bar Chart, Tree Map, Bubble Map, dan Pie Chart.
\end{abstract}

Kata kunci: Implementasi, Evaluasi, Visualisasi Data Interaktif, SIVIS LBDSE, Indikator Penilaian

\begin{abstract}
Every month the Central Statistics Agency (BPS) publishes the Indonesian Socio-Economic Data Monthly Report (LBDSE), which contains the developments of 18 data topics and their visualizations. However, the data visualization in LBDSE publications is incomplete and only static, while the existing data has quite large dimensions/variables. So that researchers think to implement interactive data visualization of LBDSE publications on SIVIS LBDSE in order to make it easier to understand the data. To assess the success of the implementation objectives, researchers will evaluate the data visualization on SIVIS LBDSE based on user ratings using 8 assessment indicators adopted from previous research. The purpose of this study is to implement interactive data visualization on LBDSE data, evaluate data visualization on SIVIS LBDSE, and find out the best data visualization for LBDSE publication categorical data. With the help of 50 respondents, they assessed that the data visualization in SIVIS LBDSE has its advantages and disadvantages, each based on the 8 assessment indicators used. But overall the respondents ranked the best data visualization for categorical data in a row, namely, Bar Chart, Tree Map, Bubble Map, and Pie Chart.
\end{abstract}

Keywords: Implementation, Evaluation, Interactive Data Visualization, SIVIS LBDSE, Assessment Indicators

\section{PENDAHULUAN}

Setiap bulan Badan Pusat Statistik (BPS) menerbitkan Publikasi Laporan Bulanan Data Sosial Ekonomi (LBDSE) Indonesia. Publikasi ini memuat perkembangan data terbaru yang dihimpun dan dirilis oleh BPS sekaligus visualisasi dari data-data tersebut. Ada 18 topik yang dibahas pada publikasi tersebut, dan setiap topik memiliki lebih dari satu data berupa tabel. Sayangnya tidak semua data yang ada pada publikasi ini memiliki visualisasi, masih banyak data yang tidak dilakukan visualisasi data. Selain itu, data-data yang ada pada publikasi ini memiliki variabel atau dimensi lebih dari satu (multidimensi). Sehingga visualisasi data yang ditampilkan juga terbatas secara visual. Visualisasi data yang ada pada publikasi berupa buku maupun buku elektronik, seperti pada publikasi ini, hanya dapat ditampilkan secara statis. Artinya pengguna tidak dapat melakukan interaksi terhadap visualisasi data yang ada.

Dari beberapa permasalahan tersebut maka dibutuhkan suatu teknik analisis data berupa visualisasi data interaktif pada publikasi LBDSE yang dapat menampilkan berbagai macam data dalam bentuk visualisasi. 
Seperti yang diungkapkan oleh Vitaly Friedman (2008) dalam bukunya bahwa "Tujuan utama dari visualisasi data adalah kemampuannya untuk memvisualisasikan data, mengkomunikasikan informasi secara jelas dan efektif." Melalui penelitian ini juga diharapkan visualisasi data interaktif yang dihasilkan dapat memudahkan pengguna dalam memahami data-data LBDSE.

Banyak pendapat yang mengatakan bahwa melalui visualisasi data, pengguna dapat memahami suatu data dengan mudah. Namun tidak semua bentuk visualisasi data berhasil membantu pengguna dalam memahami suatu data. Edward Tufte (1983) menjelaskan bahwa, "Keberhasilan dalam grafik statistik terdiri dari mengkomunikasikan ide yang kompleks dengan kejelasan, ketepatan dan efisiensi." Oleh karena itu, dibutuhkan sebuah evaluasi untuk menilai apakah suatu visualisasi berhasil menyampaikan maksud dari data tersebut atau tidak.

Berdasarkan uraian di atas, maka pada skripsi ini peneliti akan mengimplementasikan visualisasi data interaktif publikasi LBDSE pada SIVIS LDBSE (Sistem Visualisasi Laporan Bulanan Data Sosial Ekonomi). Tidak hanya itu, pada skripsi ini peneliti juga akan melakukan evaluasi terhadap visualisasi data tersebut untuk menilai apakah tujuan pengimplementasian nya dapat tercapai atau tidak. Sehingga dirumuskan tujuan pada penelitian ini yaitu sebagai berikut.

1. Untuk mengimplementasikan visualisasi data interaktif pada publikasi Laporan Bulanan Data Sosial Ekonomi (LBDSE).

2. Untuk mengetahui penilaian pengguna terhadap visualisasi data interaktif pada SIVIS LBDSE berdasarkan beberapa kelompok penilaian.

3. Untuk mengetahui perbedaan persepsi penilaian visualisasi data interaktif pada SIVIS LBDSE antara kedua kelompok responden.

4. Untuk mengetahui jenis visualisasi data interaktif terbaik terhadap data kategorik pada publikasi Laporan Bulanan Data Sosial Ekonomi (LBDSE).

\section{Penelitian Terkait}

Azra Shamim, Vimala Balakrishnan, dan Muhammad Tahir pada tahun 2014 melakukan penelitian dengan judul Evaluation of Opinion Visualization Techniques. Pada penelitian ini, mereka menggunakan beberapa matriks penilaian untuk mengevaluasi sistem visualisasi data opini. Matrik penilaian tersebut antara lain: eye pleasing, easy to understand, user-friendly, informative design, intuitive design, usefulness, comprehensiveness, comparison ability, representation style, dan pre-knowledge required. Tujuan dari penelitian tersebut yaitu menentukan peringkat sistem visualisasi opini, menyelidiki perbedaan persepsi antara kedua grup responden (peserta seminar dan kuesioner online), dan untuk mengidentifikasi matriks visualisasi yang penting. Evaluasi dilakukan oleh 146 responden yang terdiri dari 110 peserta seminar dan 36 responden yang mengisi kuesioner online. Seluruh responden tersebut diminta mengisi kuesioner untuk menilai 11 visualisasi data terpilih. Hasil yang diperoleh dari kuesioner tersebut kemudian akan dianalisis menggunakan statistik deskriptif dan independent sample t-test untuk menentukan peringkat dan menyelidiki perbedaan persepsi antara kedua grup responden.

\section{METODE}

Pada evaluasi SIVIS LBDSE dalam penelitian ini, digunakan beberapa indikator penilaian yang diadopsi dari penelitian oleh Azra Shamim, Vimala Balakrishnan, dan Muhammad Tahir pada tahun 2014. Berikut beberapa indikator penilaian yang digunakan dalam penelitian ini.

Tabel 1. Indikator Penilaian.

\begin{tabular}{cc}
\hline Kelompok Penilaian & Indikator \\
\hline Dampak Visual & Daya Tarik Visual \\
Performa Secara Keseluruhan & Kemudahan Pemahaman, Kemudahan Penggunaan, Interaktivitas \\
Desain Secara Keseluruhan & Desain Informatif \\
Kualitas Informasi & Kegunaan, Kelengkapan \\
Model Representasi Visual & Kemampuan Perbandingan \\
\hline
\end{tabular}

Penelitian dilakukan sejak bulan November 2020 sampai Januari 2021 dengan mengimplementasikan visualisasi data interaktif pada SIVIS LBDSE, kemudian dilanjutkan bulan Februari, April, dan Mei 2021 dengan mengevaluasi visualisasi data tersebut secara online. 


\section{Metode Pengumpulan Data}

Data yang digunakan dalam penelitian merupakan data primer dan data sekunder. Data primer yang digunakan dalam evaluasi SIVIS LBDSE diperoleh melalui instrumen penelitian berupa kuesioner yang dibagikan kepada responden penelitian yang mana terdiri dari kelompok responden pemula yaitu siswa/i SMA/MA di Bontang dan kelompok responden berpengalaman yaitu mahasiswa Politeknik Statistika STIS tingkat 4 jurusan Sains Data. Sedangkan data sekunder yang digunakan dalam mengimplementasikan visualisasi data interaktif pada SIVIS LBDSE diperoleh dari Publikasi Laporan Bulanan Data Sosial Ekonomi (LBDSE) Edisi Bulan Oktober, November, Desember 2020.

Sementara itu, instrumen penelitian yang digunakan dalam mengevaluasi SIVIS LBDSE pada penelitian ini yaitu kuesioner dengan menggunakan Google Form. Dimana kuesioner tersebut terdiri dari 8 blok, antara lain: Blok Penjelasan Survei; Blok Identitas Responden; dan Blok Evaluasi Bar Chart, Bubble Map, Tree Map, Line Chart, Pie Chart, dan Choropleth Map yang berisi pernyataan-pernyataan persetujuan mengenai penilaian visualisasi data pada SIVIS LBDSE berdasarkan 8 indikator yang telah ditentukan. Pernyataan persetujuan tersebut menggunakan skala Likert dengan rentang skor 1 untuk Sangat Tidak Setuju sampai skor 5 untuk Sangat Setuju. Untuk menguji keabsahan kuesioner yang digunakan, dilakukan uji validitas dan reliabilitas terhadap 8 indikator penilaian pada kuesioner Blok Evaluasi dengan menggunakan hasil pengisian kuesioner oleh 15 responden awal dari 50 responden keseluruhan. Hasilnya menjelaskan bahwa instrumen penelitian berupa 8 indikator penilaian yang digunakan pada evaluasi SIVIS LBDSE valid dan sangat reliabel.

\section{Metode Analisis}

Pada penelitian ini, dilakukan analisis deskriptif untuk menganalisis penilaian responden terhadap SIVIS LBDSE berdasarkan kuesioner yang telah dibagikan. Hasil skor penilaian SIVIS LBDSE berdasarkan 8 indikator dan 6 grafik visualisasi data akan dianalisis dan ditampilkan dalam bentuk tabel.

Selain itu, juga dilakukan analisis inferensia untuk mengetahui perbedaan persepsi penilaian visualisasi data interaktif publikasi LBDSE antara kelompok pemula dengan kelompok berpengalaman. Analisis dilakukan menggunakan uji Mann Whitney dengan hipotesis awal yaitu tidak ada perbedaan persepsi penilaian visualisasi data interaktif publikasi LBDSE antara kedua kelompok responden.

\section{HASIL DAN PEMBAHASAN}

\section{Visualisasi Data Interaktif}

Ben Shneiderman (1996) mendefinisikan sistem visualisasi data interaktif sebagai sebuah "mantra visualisasi informasi", yang mana terdiri dari overview, kemudian zoom dan filtering, terakhir details on demand. Mantra-mantra tersebut mengindikasikan bahwa visualisasi data interaktif dapat mendukung pengguna untuk menggali informasi lebih dalam mengenai data.

Tidak hanya itu, visualisasi data yang dinamis dan interaktif dapat dimanfaatkan oleh pengguna dalam mengeksplorasi data untuk dirinya sendiri (Murray, 2013). Hal tersebut dikarenakan visualisasi data interaktif yang memungkinkan pengguna untuk menampilkan berbagai macam tampilan data secara bergantian tergantung keinginan pengguna.

\section{Implementasi Visualisasi Data Interaktif pada SIVIS LBDSE}

SIVIS LBDSE (Sistem Visualisasi Laporan Bulanan Data Sosial Ekonomi) merupakan sebuah sistem visualisasi data interaktif yang menampilkan visualisasi data publikasi LBDSE secara interaktif melalui berbagai macam grafik. Data yang digunakan mencakup seluruh topik yang ada dalam publikasi LBDSE, antara lain : inflasi, pertumbuhan ekonomi, ekspor-impor, upah buruh, nilai tukar petani dan harga pangan, harga produsen dan harga perdagangan besar, indeks tendensi bisnis dan konsumen, indeks produksi industri, pariwisata, transportasi, ketenagakerjaan, kemiskinan dan tingkat ketimpangan pengeluaran penduduk, indeks pembangunan manusia, indeks perilaku anti korupsi Indonesia (IPAK), indeks demokrasi Indonesia, serta luas panen dan produksi padi.

Diagram alur penggunaan SIVIS LBDSE dijelaskan melalui gambar berikut. 


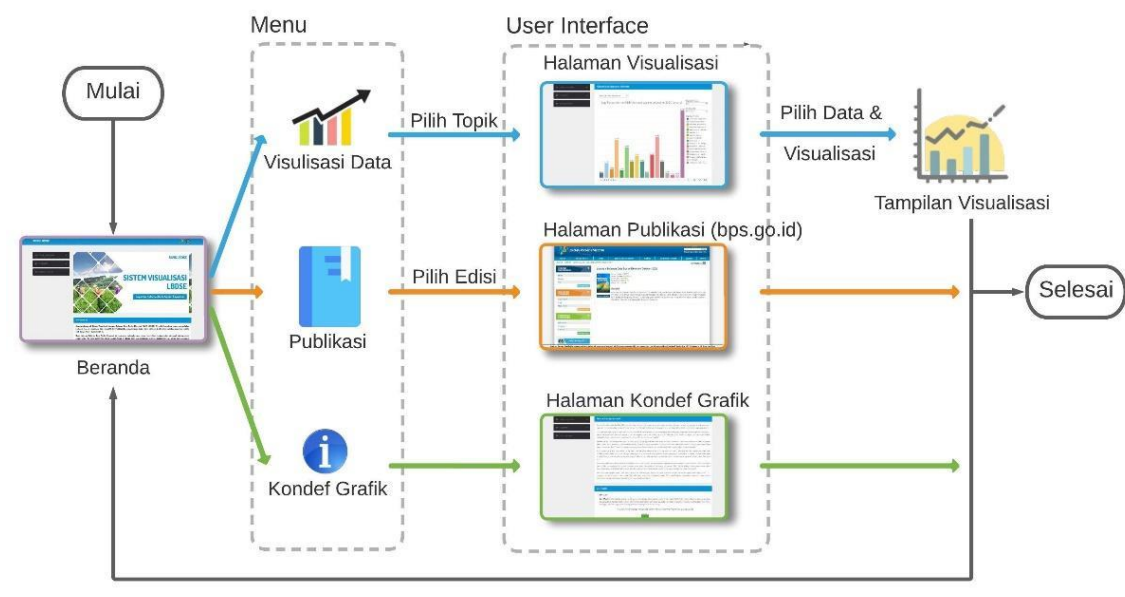

Gambar 1. Diagram Alur SIVIS LBDSE.

Pada halaman beranda, terdapat judul sistem beserta penjelasan singkat mengenai SIVIS LBDSE. Selain itu juga terdapat beberapa menu pada halaman beranda antara lain, Visualisasi Data, Publikasi, dan Kondef Grafik. Pada menu Visualisasi Data terdapat dropdown berupa 18 topik yang ada pada publikasi LBDSE, dimana ketika salah satu topik dibuka, pengguna akan diarahkan ke halaman visualisasi data dari masingmasing topik tersebut. Di halaman tersebut pengguna diminta untuk memilih data pada menu Pilih Data dan Visualisasi agar SIVIS LBDSE dapat menampilkan visualisasi data yang diminta. Selain visualisasi data interaktif, di halaman tersebut juga terdapat penjelasan mengenai konsep dan definisi dari data yang digunakan.

Selain itu, visualisasi data pada SIVIS LBDSE memiliki fitur interaktif yang berbeda-beda kegunaannya. Namun hampir setiap jenis visualisasi data menggunakan fitur interaktif yang sama. Fitur-fitur interaktif tersebut antara lain, selection, filter, detail on demand, zoom, dan search.

Fitur selection digunakan untuk memilih satu atau lebih variabel dengan cara menekan variabel yang diinginkan. Warna variabel yang tidak terpilih akan berubah menjadi sangat pudar, sedangkan warna variabel yang terpilih tidak berubah. Hal ini bertujuan untuk memudahkan pengguna dalam membedakan variabel yang terpilih dan yang tidak terpilih. Sementara itu, fitur filter pada visualisasi data SIVIS LBDSE digunakan untuk memilih data, visualisasi data, maupun waktu data yang ingin ditampilkan. Pada beberapa jenis visualisasi data, fitur filter juga digunakan untuk memilih satu atau lebih variabel yang ingin ditampilkan dalam visualisasi data. Tujuannya agar pengguna dapat fokus dalam membandingkan beberapa variabel yang diinginkan. Fitur lainnya yang ada pada SIVIS LBDSE yaitu fitur detail on demand. Fitur ini digunakan untuk menampilkan detail data dari salah satu variabel berdasarkan keinginan pengguna dengan cara menyorot variabel tersebut menggunakan kursor. Ketika salah satu variabel disorot oleh pengguna, visualisasi data akan menampilkan detail variabel tersebut, seperti nama variabel, waktu, nilai, dan lain-lain.

Selain itu, pada SIVIS LBDSE juga terdapat fitur zoom. Namun fitur ini hanya terdapat pada visualisasi data Choropleth Map. Pada visualisasi data ini fitur zoom digunakan untuk memperbesar atau memperkecil peta Indonesia yang digunakan. Fitur ini dapat digunakan dengan menekan menu zoom pada sebelah kiri atas visualisasi data atau dengan melakukan scroll menggunakan mouse maupun mousepad. Sama hal nya dengan zoom, fitur search pada SIVIS LBDSE juga hanya terdapat pada visualisasi data Choropleth Map. Melalui fitur ini, pengguna dapat mencari lokasi suatu daerah yang ada di peta Indonesia pada visualisasi data Choropleth Map. Fitur search ini dapat digunakan melalui menu search bergambar kaca pembesar pada sebelah kiri atas visualisasi data.

SIVIS LBDSE menggunakan 6 jenis visualisasi data dalam melakukan visualisasi data LBDSE antara lain, Bar Chart, Bubble Map, Tree Map, Line Chart, Pie Chart, dan Choropleth Map. Penggunaan masingmasing grafik pada SIVIS LBDSE tergantung dari bentuk data yang digunakan.

\section{Bar Chart}

Pada data kategorik, salah satu grafik yang dapat digunakan yaitu Bar Chart. Yang membedakan penggunaan nya dengan grafik lainnya dalam menampilkan data kategorik yaitu data yang memiliki nilai negatif hanya dapat ditampilkan menggunakan Bar Chart. Seperti yang dicontohkan pada Gambar 2, dimana menampilkan visualisasi data Bar Chart pada data Harga Eceran Beberapa Komoditas Bahan Pokok September-November 2020 (rupiah). Visualisasi data Bar Chart tidak hanya menampilkan data nya dalam bentuk visualisasi batang yang statis, tetapi juga menyediakan fitur-fitur interaktif di dalamnya, antara lain selection, filter, dan detail on demand. 


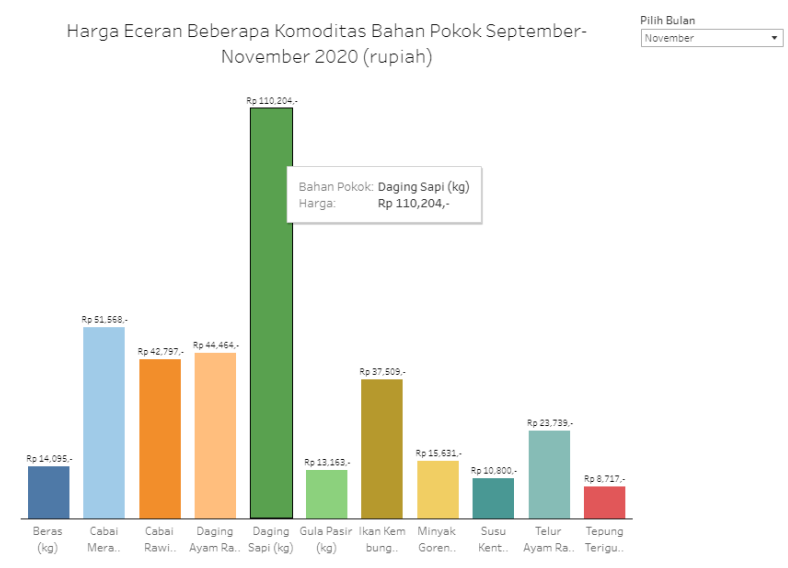

Gambar 2. Visualisasi Data Bar Chart.

\section{Bubble Map}

Visualisasi data selanjutnya pada SIVIS LBDSE yaitu visualisasi data Bubble Map. Sama hal nya dengan Bar Chart, visualisasi data Bubble Map digunakan pada data kategorik, namun yang tidak memiliki nilai negatif. Hal ini disebabkan oleh bangun datar yang digunakan berupa lingkaran, dimana semakin besar ukuran lingkaran menunjukkan semakin tinggi nilai variabel tersebut. Begitu pula sebaliknya, semakin kecil ukuran lingkaran menunjukkan nilai variabel yang semakin rendah. Selain itu visualisasi data Bubble Map juga menggunakan warna-warna yang berbeda antar lingkaran dengan tujuan menunjukkan kategori data yang berbeda-beda. Seperti halnya pada visualisasi data Bar Chart, pada visualisasi data Bubble Map juga terdapat beberapa fitur-fitur interaktif yang dapat digunakan pengguna. Fitur-fitur tersebut antara lain, selection, filter, dan detail on demand.

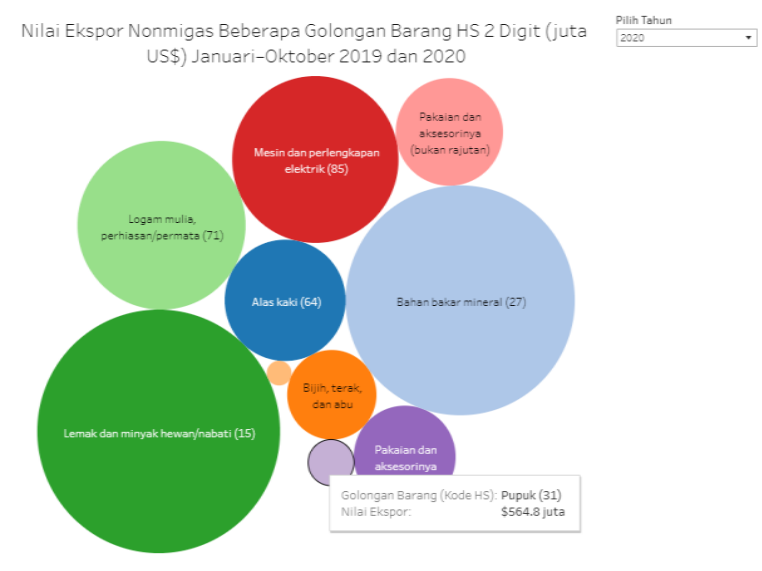

Gambar 3. Visualisasi Data Bubble Map.

\section{Tree Map}

Sama hal nya dengan visualisasi data Bubble Map, data yang digunakan pada visualisasi data Tree Map juga merupakan data kategorik yang tidak memiliki nilai negatif. Hal ini disebabkan oleh komponen Tree Map yang terdiri dari segi empat yang dikumpulkan berdasarkan variabel-variabel pada data yang digunakan sampai membentuk segi empat berukuran besar. Semakin tinggi nilai variabel maka semakin besar ukuran dan semakin gelap warna segi empat pada variabel tersebut. Begitu pula sebaliknya, semakin kecil nilai suatu variabel maka semakin kecil ukuran dan semakin cerah warna segi empat tersebut. Seperti contoh yang ditampilkan pada Gambar 4, dimana gambar tersebut menampilkan visualisasi data PDB Atas Dasar Harga Berlaku Menurut Lapangan Usaha, Tahun 2017-2020 (triliun rupiah).

Selain itu, visualisasi data Tree Map juga memiliki beberapa fitur interaktif berupa selection, filter, dan detail on demand. 


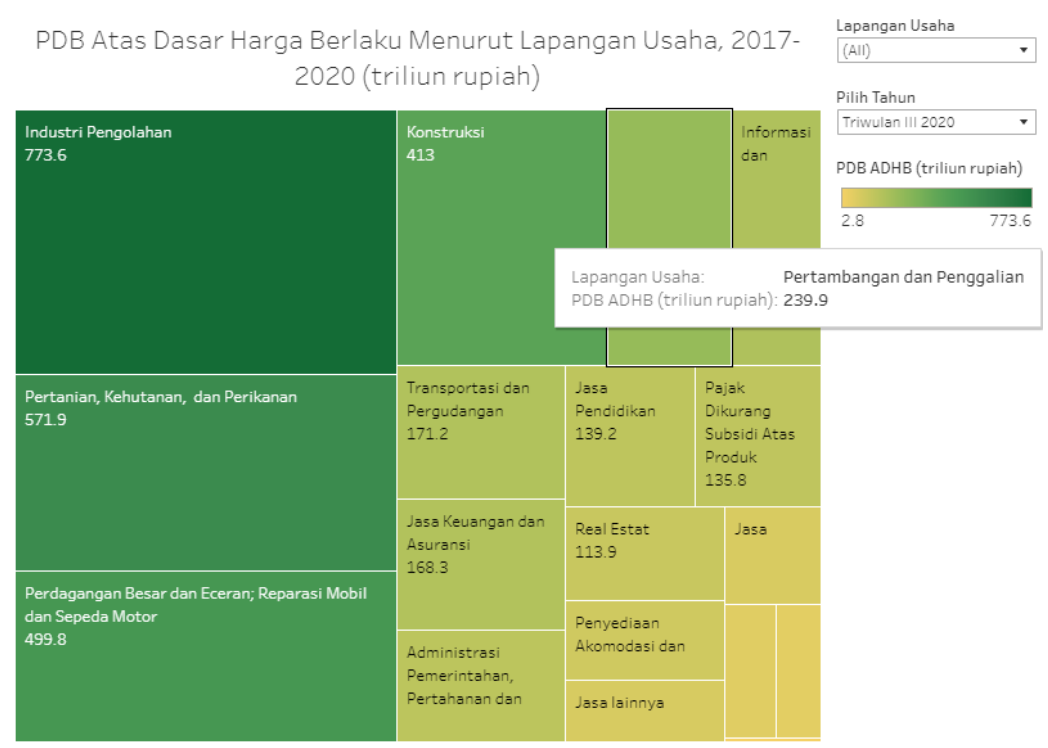

Gambar 4. Visualisasi Data Tree Map.

\section{Line Chart}

Sementara itu, Line Chart digunakan untuk data yang memiliki trend, baik bulanan, triwulanan, maupun tahunan. Pada visualisasi data Line Chart dalam SIVIS LBDSE, peneliti menambahkan visualisasi animasi untuk melihat nilai pada periode waktu tertentu. Dengan animasi ini, poin-poin data pada Line Chart dapat bergerak secara otomatis mengikuti periode waktu data tersebut. Sebagai contoh dapat dilihat Gambar 5 berikut.

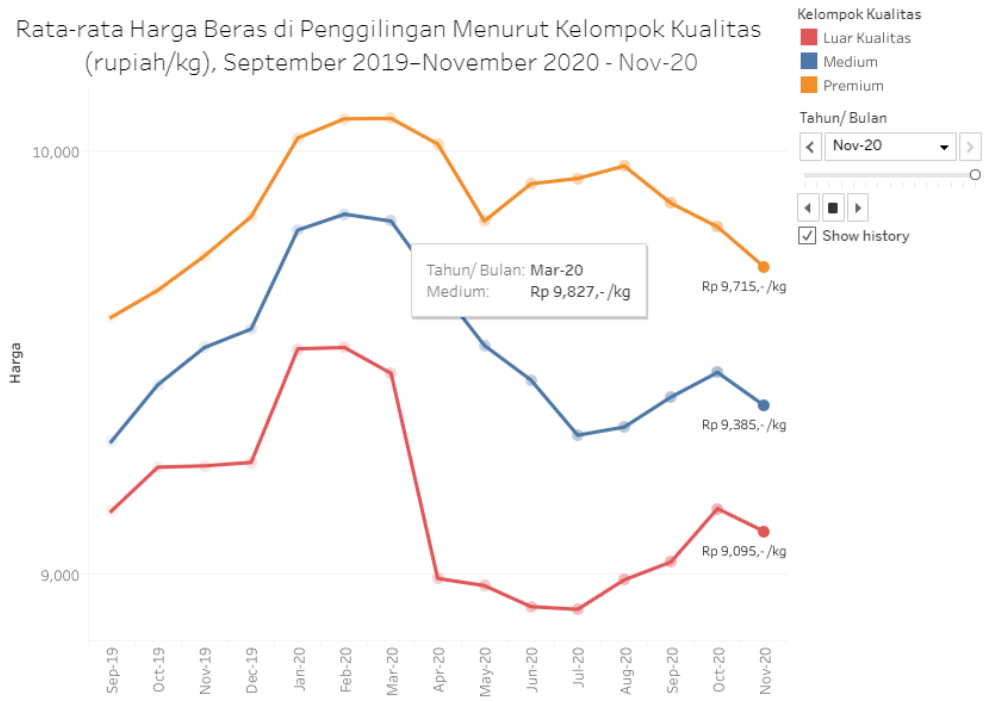

Gambar 5. Visualisasi Data Line Chart.

Gambar tersebut menampilkan visualisasi data Line Chart pada data Rata-rata Harga Beras di Penggilingan Menurut Kelompok Kualitas (rupiah/kg), Bulan September 2019-November 2020. Ketika tombol play pada menu sebelah kanan ditekan, poin-poin data harga beras setiap kelompok kualitas akan bergerak secara otomatis mulai bulan September 2019 sampai November 2020. Selain itu, pada visualisasi data ini juga memiliki beberapa fitur interaktif, antara lain selection dan detail on demand.

\section{Pie Chart}

Selain itu, pada SIVIS LBDSE juga terdapat visualisasi data Pie Chart untuk menampilkan data kategorik. Namun yang membedakan dengan Bar Chart, Bubble Map, dan Tree Map, data yang digunakan pada Pie Chart berupa persentase dimana total persentase harus $100 \%$. Hal ini bertujuan untuk membentuk Pie Chart menjadi bangun datar lingkaran yang sempurna. Salah satu contoh penggunaan Pie Chart dapat dilihat pada Gambar 6 . 




Gambar 6. Visualisasi Data Pie Chart.

Gambar 6 menampilkan visualisasi data Pie Chart pada data Peranan Wilayah/Pulau dalam Pembentukan PDB Nasional (persen). Visualisasi data tersebut menyediakan fungsi interaktif berupa filter, selection, dan detail on demand.

\section{Choropleth Map}

Sementara itu, Choropleth Map digunakan pada data yang memiliki variabel geografis. Choropleth Map menampilkan data dalam bentuk peta, dengan menggunakan warna-warna yang berbeda antar daerah. Hal ini bertujuan untuk memudahkan pengguna dalam membedakan data antar daerah tersebut. Semakin gelap warna pada suatu daerah menunjukkan nilai data yang semakin tinggi. Begitu pula sebaliknya, jika warna pada suatu daerah semakin cerah menunjukkan data pada daerah tersebut semakin rendah nilainya.

Selain itu, visualisasi data Choropleth Map pada SIVIS LBDSE ini juga menggunakan beberapa fungsi interaktif, antara lain zoom, filter, search, selection, dan detail on demand. Sebagai contoh dapat dilihat pada Gambar 7, yang menampilkan visualisasi data Indeks Demokrasi Indonesia (IDI) Berdasarkan Aspek dan Provinsi Tahun 2019.



Gambar 7. Visualisasi Data Choropleth Map.

\section{Evaluasi Visualisasi Data Interaktif pada SIVIS LBDSE}

Selain mengimplementasikan visualisasi data interaktif, pada penelitian ini juga dilakukan evaluasi terhadap masing-masing jenis visualisasi data yang digunakan dalam SIVIS LBDSE. Evaluasi dilakukan berdasarkan kelompok-kelompok penilaian beserta indikatornya yang diadopsi dari penelitian sebelumnya.

Dengan mengacu pada penghitungan skor uji SUS, hasil penilaian setiap responden pada penelitian ini akan dikali 2.5 dan dihitung rata-rata untuk setiap indikator penilaian dan visualisasi data. Selanjutnya, ratarata skor penilaian untuk setiap indikator penilaian dan visualisasi data tersebut dijumlahkan untuk mendapatkan skor akhir masing-masing visualisasi data. Skor masing-masing visualisasi data dapat dilihat pada Tabel 2.

Dari hasil penilaian visualisasi data berdasarkan 8 indikator yang ditampilkan pada Tabel 2, memperlihatkan bahwa kedua kelompok responden lebih tertarik dengan tampilan visualisasi data berupa Choropleth Map.

Sementara itu, visualisasi data yang mudah dipahami oleh kedua kelompok responden yaitu visualisasi data Bar Chart dan Line Chart. Sedangkan visualisasi data yang paling mudah digunakan oleh kelompok pemula pada SIVIS LBDSE yaitu visualisasi data Line Chart. Demikian pula bagi kelompok berpengalaman, mereka menilai bahwa visualisasi data yang paling mudah digunakan pada SIVIS LBDSE yaitu visualisasi 
data Line Chart dan Bar Chart. Indikator lainnya yaitu indikator "Interaktivitas", dimana kedua kelompok responden sepakat bahwa visualisasi data yang paling interaktif yaitu visualisasi data Line Chart.

Selain itu, berdasarkan indikator "Desain Informatif" dapat disimpulkan bahwa menurut kelompok responden pemula maupun kelompok responden berpengalaman visualisasi data yang memiliki desain yang paling informatif yaitu visualisasi data Line Chart.

Pada indikator "Kegunaan" kelompok responden pemula menilai bahwa visualisasi data yang memiliki informasi paling berguna dalam meningkatkan pemahaman terhadap data yaitu visualisasi data Bar Chart. Berbeda dengan kelompok responden berpengalaman yang menilai visualisasi data paling berguna yaitu Choropleth Map dan Line Chart. Sementara itu, berdasarkan hasil penilaian pada indikator "Kelengkapan" visualisasi data yang memiliki informasi paling lengkap menurut kelompok responden pemula yaitu Tree Map dan Line Chart, sedangkan menurut kelompok responden berpengalaman yaitu visualisasi data Line Chart.

Tabel 2. Hasil Penilaian Visualisasi Data Interaktif.

\begin{tabular}{|c|c|c|c|c|c|c|c|}
\hline Indikator & Responden & $\begin{array}{c}\text { Bar } \\
\text { Chart }\end{array}$ & $\begin{array}{c}\text { Bubble } \\
\text { Map }\end{array}$ & $\begin{array}{l}\text { Tree } \\
\text { Map }\end{array}$ & $\begin{array}{l}\text { Line } \\
\text { Chart }\end{array}$ & $\begin{array}{c}\text { Pie } \\
\text { Chart }\end{array}$ & $\begin{array}{c}\text { Choropleth } \\
\text { Map }\end{array}$ \\
\hline \multirow{2}{*}{ Daya tarik visual } & Kelompok pemula & 10.7 & 11.2 & 10.5 & 10.8 & 10.9 & 11.2 \\
\hline & Kelompok berpengalaman & 10 & 10.2 & 10.4 & 10.3 & 10 & 11.2 \\
\hline \multirow{2}{*}{ Kemudahan Pemahaman } & Kelompok pemula & 10.7 & 10.4 & 10.4 & 10.7 & 10.3 & 10.4 \\
\hline & Kelompok berpengalaman & 11.2 & 10 & 10.3 & 11.2 & 10.1 & 10.9 \\
\hline \multirow{2}{*}{ Kemudahan Penggunaan } & Kelompok pemula & 10.3 & 10.5 & 10.6 & 11.1 & 10.5 & 9.9 \\
\hline & Kelompok berpengalaman & 11.3 & 10.7 & 10.8 & 11.3 & 10.7 & 11.2 \\
\hline \multirow{2}{*}{ Desain Informatif } & Kelompok pemula & 11 & 10.7 & 11 & 11.2 & 10.6 & 10.6 \\
\hline & Kelompok berpengalaman & 10.6 & 10.2 & 10.4 & 11.5 & 10.2 & 10.5 \\
\hline \multirow{2}{*}{ Kegunaan } & Kelompok pemula & 10.8 & 9.7 & 10.3 & 10.3 & 9.7 & 10.4 \\
\hline & Kelompok berpengalaman & 10.4 & 10.6 & 10.2 & 11.1 & 10.4 & 11.1 \\
\hline \multirow{2}{*}{ Kelengkapan } & Kelompok pemula & 10.6 & 10 & 10.8 & 10.8 & 10.1 & 10.4 \\
\hline & Kelompok berpengalaman & 10.4 & 10 & 10.6 & 11.1 & 10.3 & 10.8 \\
\hline \multirow{2}{*}{ Kemampuan Perbandingan } & Kelompok pemula & 11 & 10.9 & 10.7 & 10.5 & 10.7 & 10.1 \\
\hline & Kelompok berpengalaman & 10.7 & 10.5 & 10.7 & 11.2 & 10.4 & 10.7 \\
\hline \multirow{2}{*}{ Interaktivitas } & Kelompok pemula & 10.1 & 10 & 9.9 & 10.2 & 9.6 & 10 \\
\hline & Kelompok berpengalaman & 11 & 10.8 & 11.2 & 11.5 & 11 & 11.4 \\
\hline \multicolumn{2}{|c|}{ SKOR } & 85.4 & 83.2 & 84.4 & 87.4 & 82.75 & 85.4 \\
\hline
\end{tabular}

Indikator penilaian terakhir yang digunakan yaitu "Kemampuan Perbandingan", dimana kelompok responden pemula menilai visualisasi data Bar Chart memiliki kemampuan perbandingan yang paling tinggi. Berbeda dengan kelompok responden berpengalaman yang menilai visualisasi data Line Chart yang memiliki kemampuan perbandingan paling tinggi.

Dari penghitungan skor untuk masing-masing indikator penilaian dan visualisasi data yang telah dijelaskan sebelumnya, dapat disimpulkan mengenai kategori kualitas masing-masing visualisasi data. Pengkategorian kualitas visualisasi data mengacu pada kelompok peringkat skor SUS dari penelitian yang dilakukan oleh A. Bangor, P.T. Kortum, dan J.T. Miller dengan judul "Determining What Individual SUS Scores Mean: Adding an Adjective Rating Scale" seperti yang ditampilkan pada Gambar 8.

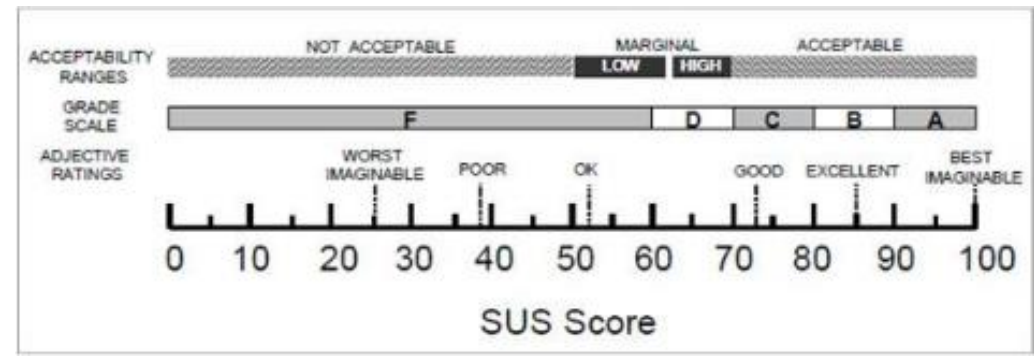

Gambar 8. Kelompok Peringkat Skor SUS. 
Berdasarkan Gambar 8 dapat dikelompokkan skor dengan nilai kurang dari 25 tergolong Worst Imaginable, 25 - 39 tergolong Poor, 39 - 52 tergolong Ok, 52 - 73 tergolong Good, $73-85$ tergolong Excellent, dan lebih dari 85 tergolong Best Imaginable.

Berdasarkan total skor yang diperoleh masing-masing visualisasi data pada Tabel 2, dapat disimpulkan bahwa Line Chart tergolong kategori Best Imaginable Visualization. Begitu pula visualisasi data Bar Chart dan Choropleth Map yang juga tergolong kategori Best Imaginable Visualization. Hal tersebut disebabkan oleh skor yang diperoleh ketiga visualisasi data tersebut bernilai lebih dari 85. Sementara itu, 3 visualisasi data lainnya yaitu Bubble Map, Tree Map, dan Pie Chart tergolong kategori Excellent Visualization karena memperoleh skor antara $73-85$.

\section{Perbedaan Persepsi Penilaian Kelompok Pemula dan Berpengalaman}

Untuk mengetahui perbedaan persepsi penilaian visualisasi data interaktif pada SIVIS LBDSE antara kelompok responden pemula dan kelompok responden berpengalaman, peneliti melakukan uji Mann Whitney dengan hipotesis awal yaitu tidak ada perbedaan persepsi penilaian antara kedua kelompok responden. Data yang digunakan dalam uji ini yaitu skor total seluruh indikator penilaian untuk seluruh visualisasi data interaktif pada SIVIS LBDSE yang dinilai oleh masing-masing responden.

Dengan menggunakan tingkat signifikansi sebesar 5\% peneliti melakukan uji Mann Whitney dengan penghitungan manual maupun dengan menggunakan aplikasi IBM SPSS Statistics versi 26. Output uji Mann Whitney menggunakan IBM SPSS Statistics 26 dapat dilihat pada tabel berikut.

Tabel 3. Hasil Uji Mann Whitney.

\begin{tabular}{cc}
\hline Nilai & Total Skor \\
\hline Mann-Whitney U & 297 \\
Wilcoxon W & 622 \\
Z & $-0,301$ \\
Asymp. Sig. (2-tailed) & 0,763 \\
\hline
\end{tabular}

Sumber: Output SPSS

Berdasarkan Tabel 3 dapat dilihat bahwa nilai $p$-value sebesar 0,763 dan $\mathrm{Z}$ hitung sebesar $-0,301$. Oleh sebab nilai $p$-value yang lebih besar dari 0,05 maka diputuskan bahwa hipotesis awal diterima.

Sehingga dapat disimpulkan bahwa dengan tingkat signifikansi sebesar 5\% tidak ada perbedaan persepsi penilaian antara kelompok responden pemula dan kelompok responden berpengalaman dalam menilai dan mengevaluasi visualisasi data interaktif pada SIVIS LBDSE. Artinya visualisasi data interaktif pada SIVIS LBDSE dapat digunakan oleh seluruh pengguna, baik pengguna yang telah berpengalaman maupun pengguna yang masih awam terhadap visualisasi data.

\section{Visualisasi Data Kategorik Terbaik}

Dalam membandingkan data kategorik pada publikasi LBDSE, SIVIS LBDSE menggunakan 4 jenis visualisasi data yakni Bar Chart, Bubble Map, Tree Map, dan Pie Chart. Pada visualisasi data Bar Chart, digunakan tinggi batang untuk menunjukkan tinggi rendahnya nilai masing-masing kategori dan warna yang berbeda-beda untuk menunjukkan perbedaan setiap kategori data. Begitu pula pada visualisasi data Bubble Map dan Pie Chart dimana kedua visualisasi data tersebut juga menggunakan luas area untuk menunjukkan tinggi rendahnya nilai masing-masing kategori serta warna pada visualisasi untuk membedakan setiap kategori pada data. Sementara itu, visualisasi data Tree Map menggunakan luas area dan warna untuk menunjukkan tinggi rendahnya nilai suatu kategori/variabel.

Berdasarkan analisis penilaian terhadap masing-masing visualisasi data dan indikator penilaian yang telah dijelaskan sebelumnya, peneliti dapat menyimpulkan peringkat visualisasi data terbaik untuk data kategorik menurut rata-rata skor yang diberikan kedua kelompok responden. Berdasarkan Tabel 2, penilaian visualisasi data pada SIVIS LBDSE memperlihatkan bahwa peringkat visualisasi data terbaik terhadap data kategorik publikasi LBDSE secara berturut-turut yaitu Bar Chart, Tree Map, Bubble Map, dan terakhir Pie Chart. Sehingga dapat disimpulkan bahwa visualisasi data terbaik untuk membandingkan data kategorik menurut penilaian gabungan kedua kelompok responden yaitu visualisasi data Bar Chart. Sedangkan visualisasi data yang paling tidak baik yaitu visualisasi data Pie Chart.

Penilaian ini sejalan dengan teori yang dikemukakan oleh Cleveland and McGill (1984) dimana mereka melakukan evaluasi keakuratan berbagai properti, elemen grafis, dan substrat spasial yang dapat digunakan dalam menilai data kuantitatif. Hasilnya menjelaskan bahwa elemen grafik dan spasial yang paling akurat 
dalam melakukan visualisasi data kuantitatif secara berturut-turut yaitu Position, Length, Orientation, Area, Volume, Color and texture.

Ricardo Mazza (2009) menjelaskan elemen grafis adalah segala sesuatu yang muncul dan terlihat pada ruang visualisasi. Ada empat jenis elemen grafis yang biasa digunakan pada visualisasi data yakni titik, garis, permukaan, dan volume. Sementara itu, properti grafis merupakan sifat dari elemen grafis yang membuat retina mata manusia sangat sensitif terhadapnya. Hal itulah yang membuat properti grafis juga disebut variabel retinal. Properti grafis yang paling umum digunakan adalah ukuran, orientasi, warna, tekstur, dan bentuk.

Seperti yang telah dijelaskan sebelumnya bahwa urutan visualisasi data terbaik menurut penilaian gabungan seluruh responden secara berturut-turut yaitu Line Chart, Choropleth Map, Bar Chart, Tree Map, Bubble Map, dan terakhir Pie Chart. Hal ini sejalan dengan tingkat keakuratan elemen dan properti grafis yang digunakan dalam menilai data kuantitatif menurut Cleveland dan McGill, yang mana Line Chart menggunakan elemen posisi titik, Choropleth Map menggunakan elemen warna, Bar Chart menggunakan elemen panjang/tinggi, Tree Map menggunakan elemen luas area dan warna, Bubble Map menggunakan elemen luas area, dan Pie Chart menggunakan elemen luas area. Sehingga dapat disimpulkan visualisasi data terbaik yang dinilai oleh seluruh responden juga mengindikasikan visualisasi data yang semakin akurat.

\section{KESIMPULAN}

Pada penelitian ini, peneliti berhasil mengimplementasikan visualisasi data interaktif pada data LBDSE melalui 6 jenis visualisasi data interaktif pada SIVIS LBDSE antara lain, Bar Chart, Bubble Map, Tree Map, Line Chart, Pie Chart, dan Choropleth Map. Tidak hanya itu, peneliti juga telah melakukan evaluasi terhadap implementasi visualisasi data interaktif tersebut. Dengan menggunakan 8 indikator penilaian, disimpulkan bahwa visualisasi data Bar Chart, Line Chart, dan Choropleth Map tergolong ke dalam kategori Best Imaginable Visualization. Sedangkan 3 visualisasi data lainnya yaitu Bubble Map, Tree Map, dan Pie Chart tergolong kategori Excellent Visualization. Berdasarkan hasil evaluasi juga, peneliti melakukan uji Mann Whitney dan menyimpulkan bahwa tidak ada perbedaan persepsi penilaian visualisasi data interaktif pada SIVIS LBDSE antara kelompok responden pemula dan kelompok responden berpengalaman. Selanjutnya, hasil evaluasi visualisasi data interaktif menjelaskan bahwa seluruh responden menilai visualisasi data terbaik terhadap data kategorik publikasi LBDSE secara berturut-turut yaitu Bar Chart, Tree Map, Bubble Map, dan terakhir Pie Chart.

Dengan Sistem Visualisasi LBDSE (SIVIS LBDSE) yang telah dibangun dan dievaluasi ini diharapkan dapat membantu pengguna LBDSE dalam memahami data-data LBDSE dengan mudah dan cepat melalui visualisasi data yang lengkap.

Berdasarkan penelitian yang telah dilakukan, peneliti menyadari masih terdapat beberapa kekurangan yang menjadi kelemahan dari penelitian ini. Maka dari itu, peneliti memiliki beberapa saran untuk penelitian selanjutnya yaitu membuat basis data untuk penyimpanan data-data LBDSE yang diterbitkan oleh BPS agar memudahkan dalam pembuatan visualisasi data interaktif. Basis data tersebut diharapkan juga terintegrasi dengan Publikasi LBDSE dan SIVIS LBDSE agar memudahkan dalam memperbarui visualisasi data ketika terdapat pembaharuan data LBDSE. Selanjutnya, untuk menilai indikator kemudahan pemahaman dalam evaluasi visualisasi data dapat dilakukan dengan memberikan soal kepada responden yang berkaitan dengan data yang digunakan dan dihitung waktu responden dalam menjawab soal tersebut. Hal ini bertujuan agar penilaian pada indikator ini lebih objektif.

\section{DAFTAR PUSTAKA}

Badan Pusat Statistik. 2020. Laporan Bulanan Data Sosial Ekonomi. Oktober. BPS. Jakarta. Badan Pusat Statistik. 2020. Laporan Bulanan Data Sosial Ekonomi. November. BPS. Jakarta. Badan Pusat Statistik. 2020. Laporan Bulanan Data Sosial Ekonomi. Oktober. BPS. Desember.

Bai , X., White, D., \& Sundaram, D. (2011). Purposeful Visualization. Proceedings of the 44th Hawaii International Conference on System Sciences (pp. 1-10). New York: IEEE Computer Society.

Cleveland, William S. \& McGill, Robert. (1984). Graphical Perception: Theory, Experimentation, and Application to the Development of Graphical Methods. Journal of the American Statistical Association, 79(387), 531-554.

Downer, T., Gray, M., \& Andersen, P. (2020). Three-Dimensional Technology: Evaluating the Use of Visualisation in Midwifery Education. Clinical Simulation in Nursing, 39(C), 27-32.

Mazza, Riccardo. (2009). Introduction to Informasi Visualization. London: Springer-Verlag London. Murray, Scott. (2013). Interactive Data Visualization for the Web. Sebastopol: O'Reilly Media, Inc. 
Nguyen, Q. V., Miller, N., Arness, D., Huang, W., Huang, M. L., \& Simoff, S. (2020). Evaluation on interactive visualization data with scatterplots. Visual Informatics.

Shamim, A., Balakrishnan, V., \& Tahir, M. (2014). Evaluation of Opinion Visualization Techniques. Information Visualization, 14(4), 1-20.

Shneiderman, Ben. The Eyes Have It: A Task by Data Type Taxonomy for Information Visualizations. In Proceedings of the IEEE Symposium on Visual Languages, pages 336-343, Washington. IEEE Computer Society Press, 1996. http://citeseer.ist.psu.edu/409647.html

Tufte, Edward. (1983). The Visual Display of Quantitative Information. Cheshire, Connecticut: Graphics Press. ISBN 0961392142.

Vitaly Friedman, "Data Visualization and Infographics." Smashing Magazine, January 14, 2008. https://www.smashingmagazine.com/2008/01/monday-inspiration-data-visualization-and-infographics 